\title{
Enseñanza de la historia en el nivel secundario en Argentina: herencias, rupturas, invenciones e inercias
}

\author{
Maria Paula Gonzalez*
}

\section{Resumen}

\begin{abstract}
Este trabajo analiza las configuraciones actuales de la historia como disciplina escolar en el nivel secundario en Argentina, tomando particularmente los propósitos y las actividades que se enuncian, se sugieren y se practican. A través de diversas fuentes normativas, pedagógicas y docentes, el análisis muestra rupturas, inercias, invenciones y herencias.
\end{abstract}

Palabras claves: Enseñanza. Historia. Prácticas. Propósitos. Actividades.

\section{Introducción}

Durante más de cien años, la historia escolar apostó a la formación de ciudadanos nacionalistas y patrióticos, acentuó el estudio de la dimensión política de las sociedades en el tiempo - especialmente de las instituciones y de los héroes y las epopeyas independentistas del siglo XIX - y priorizó la descripción y memorización de datos fácticos a través del trabajo con manuales escolares y fuentes escritas (LANZA, 1993; BRASLAVSLY, 1994; ROMERO, 2004; FINOCCHIO, 1999; DE AMÉZOLA, 2008).

Pero hace más de veinte años que la historia escolar viene transformándose, no sólo por la generación de nuevas regulaciones educativas y renovados diseños curriculares, sino también por el impacto de intensas mutaciones sociales y culturales, a saber, los cambios tecnológicos y comunicacionales de la era digital (CASTELLS, 1998) que se traducen, por ejemplo, en la introducción de las Tecnologías

\footnotetext{
Recebido: 12/06/2014 - Aprovado: 07/07/2014

http://dx.doi.org/10.5335/rep.v21i2.4300
}

Graduada en Historia por la Universidad de Buenos Aires (Argentina). Doctora por la Universidad Autónoma de BarceIona en el Programa de Didáctica de las Ciencias Sociales (España). Actualmente se desempeña como investigadora docente adjunta en la Universidad Nacional de General Sarmiento y como investigadora de Carrera del Consejo Nacional de Investigaciones Científicas y Técnicas (Argentina). E-mail: gonzalezamorena@gmail.com. 
de la Información y la Comunicación (TIC). En una escala más amplia, además, el sistema educativo argentino ha estallado en fragmentos institucionales desiguales (TIRAMONTI, 2004; KESSLER, 2002), se observan tensiones en torno al sentido en la tarea pedagógica, la institucionalidad y la identidad escolar (DUSSEL; FINOCCHIO, 2001), resultan evidentes los desafíos de la obligatoriedad del nivel secundario establecido hace pocos años en nuestro país (TIRAMONTI; MONTES, 2008), así como se perciben transformaciones en la identidad docente y las subjetividades juveniles (BRITO, 2010; URRESTI, 2008), entre otras muchas cuestiones.

En este contexto de múltiples cambios y desafíos nuevos, la pregunta que intentaré responder es cómo se está configurando actualmente la historia como disciplina escolar en el nivel secundario. ${ }^{1}$ La motivación principal es mostrar no solo lo que perdura sino también lo que ha cambiado y lo que todavía se está transformando e inventando advirtiendo la mixtura de cambios y continuidades.

En este escrito haré foco en dos aspectos de la historia como disciplina escolar: su función y funcionamiento, es decir, los sentidos enunciados y asumidos así como las actividades y ejercicios que se sugieren y ponen en juego en el cotidiano escolar. Para ello, seguidamente presentaré el marco teórico asumido así como las fuentes consultadas para luego dar paso a la presentación y análisis de las evidencias encontradas.

La conclusión principal (y provisoria) de esta indagación es que la enseñanza de la historia en el nivel medio en la actualidad muestra un repertorio de herencias, inercias, rupturas e invenciones que evidencian el quiebre del código disciplinar que, como señalábamos al principio, rigió a esta asignatura durante más de cien años.

\section{Perspectiva teórica, empírica y contextual}

Desde el punto de vista teórico, propongo analizar la historia escolar hoy desde algunos conceptos claves de la historia de la educación, muy relacionados con los aportes de la historia cultural, comenzando por una noción que se ha revelado como muy potente y fructífera: "cultura escolar". La misma ha sido definida como "el conjunto de normas que definen los saberes a enseñar y los comportamientos a inculcar, y el conjunto de prácticas que permiten la transmisión y la asimilación de dichos saberes y la incorporación de estos comportamientos" (JULIA, 2001, p. 9).

Para Antonio Viñao, la cultura escolar

[...] estaría constituida por un conjunto de teorías, ideas, principios, normas, pautas, rituales, inercias, hábitos y prácticas (formas de hacer y pensar, mentalidades y comportamientos) sedimentadas a lo largo del tiempo en forma de tradiciones, regularidades y reglas de juego no puestas en entredicho, y compartidas por sus actores, en el seno de las instituciones educativas. Tradiciones, regularidades y reglas de juego que se trasmiten de generación 
en generación y que proporcionan estrategias: a) para integrarse en dichas instituciones e interactuar en las mismas; b) para llevar a cabo, sobre todo en el aula, las tareas cotidianas que de cada uno se esperan, y hacer frente a las exigencias y limitaciones que dichas tareas implican o conllevan; y c) para sobrevivir a las sucesivas reformas, reinterpretándolas y adaptándolas, desde dicha cultura, a su contexto y necesidades (VIÑAO, 2002, p. 59).

Dentro de la cultura escolar, sobresale un producto en particular que es las disciplinas escolares:

Las disciplinas, materias o asignaturas son una de las creaciones más genuinas de la cultura escolar. Muestran su poder creativo. Poseen, además, su propia historia. No son, pues, entidades abstractas con una esencia universal y estática. Nacen y evolucionan. Se transforman o desaparecen, se desgajan y se unen, se rechazan y se absorben. Cambian sus denominaciones, modifican sus contenidos. Son, así vistas, organismos vivos. Y, al mismo tiempo, espacios de poder, de un poder a disputar. Espacios donde se entremezclan intereses y actores, acciones y estrategias (VIÑAO, 2002, p. 60).

André Chervel (1991) ha señalado que se puede considerar tres cuestiones en la exploración de una disciplina escolar: origen, función y funcionamiento.

El origen alude a los saberes que una disciplina transmite. Al respecto, Chervel señala que los contenidos de enseñanza no son productos externos - resultado de una vulgarización y transposición de saberes académicos - sino una invención, una creación histórica de la propia escuela, por y para la escuela. Esta mirada que propone Chervel supone el esfuerzo de rastrear dentro de la escuela los elementos para la caracterizar las disciplinas escolares y así superar las miradas externas restringidas a los documentos curriculares o los materiales didácticos. De allí el interés en retomarla aunque entiendo que otras perspectivas que estudian los condicionamientos de las luchas políticas y sociales - tal como ha propuesto Goodson (1991) - y de los campos disciplinares - tal como ha señalado Chevallard (1997) pueden colaborar en una mirada holística (histórica, social y epistemológica) de la construcción de las disciplinas escolares.

Respecto a la función, este autor señala que tal aspecto alude a las finalidades que se le han asignado las disciplinas en general y los objetivos de cada una de ellas en particular. En tal sentido, la exploración de los sentidos y propósitos enunciados y asumidos para la historia como disciplina escolar permiten reconstruir esta dimensión.

En relación con el funcionamiento, el mismo autor indica que una mirada de largo plazo permite ver que las disciplinas escolares están constituidas "por una combinación, en proporciones variables según los casos, de diversos elementos: una enseñanza de exposición, ejercicios, prácticas de motivación e incitación al estudio y un aparato docimológico" (CHERVEL, 1991, p. 94). A esto, el autor agrega que "si los contenidos explícitos constituyen el eje central de la disciplina enseñada, el ejercicio 
de ellos es la contrapartida casi indispensable [...] Sin ejercicio, y sin el correspondiente control de éste, no es posible fijar una disciplina" (CHERVEL, 1991, p. 90).

En función de lo anterior, y como ya señalé, en este trabajo me abocaré puntualmente al análisis de dos de las dimensiones señaladas por Chervel, esto es, la función de la historia como disciplina escolar - sentidos, finalidades, objetivos o propósitos - y su funcionamiento - considerando las actividades que se están planteando en la actualidad. ${ }^{2}$

Para ello, y desde el punto de vista empírico, exploro un conjunto de fuentes que dan cuenta de las tres culturas de la escuela (ESCOLANO, 1999): la cultura "político-normativa", asociada al discurso producido en los entornos administrativos y burocráticos; la cultura "pedagógica", generada en el mundo académico; y la cultura "empírico práctica" de los docentes, elaborada por los enseñantes en el ejercicio de su profesión. ${ }^{3}$ Cada una de estas culturas muestra grados variables de autonomía, correspondencia e interdependencia lo que significa que no existe una por fuera de la otra: antes bien, en cada una ellas es posible advertir trazos de las otras. Siendo las disciplinas escolares productos de la cultura escolar, entiendo que las mismas pueden reconstruirse desde esas mismas fuentes. Parece claro que el funcionamiento de una disciplina no puede derivarse de lo señalado por los documentos político-normativos o pedagógicos pero, del mismo modo, tampoco puede reconstruirse solo desde las fuentes de la cultura docente.

En relación con lo anterior, Raimundo Cuesta (1997) ha señalado una noción afín que nos ayuda en la justificación del abordaje empírico: "código disciplinar". Tal concepto es definido como

[...] una tradición social configurada históricamente y compuesta de un conjunto de ideas, valores, suposiciones y rutinas, que legitiman la función educativa atribuida a la Historia y que regulan el orden de la práctica de su enseñanza. El código disciplinar de la Historia alberga, pues, las especulaciones y retóricas discursivas sobre su valor educativo, los contenidos de enseñanza y los arquetipos de práctica docente, que se suceden en el tiempo y que se consideran, dentro de la cultura, valiosos y legítimos (CUESTA, 1997, p. 20).

En otras palabras, el código disciplinar está compuesto no sólo por ideas o principios (científicas, pedagógicas, políticas, etc.) sobre el valor de la materia escolar, sino también por un conjunto de prácticas, es decir, que se construye a partir de lo señalado en la normativa, lo sugerido en la pedagogía y lo practicado por los docentes.

Como fuentes de la cultura política-normativa, he considerado la Ley Nacional de Educación 26206 de 2006; la Ley de Educación de la Provincia de Buenos Aires 13688 de 2007; los Núcleos de Aprendizaje Prioritario (NAP) prescritos por el Ministerio de Educación en 2006; los Lineamientos Políticos y Estratégicos de la Secundaria Obligatoria de Provincia de Buenos Aires y los Diseños curricula- 
res para ese nivel y de esa misma jurisdicción vigentes en 2013. Para la cultura "pedagógica", he revisado un corpus de libros de textos escolares; ${ }^{4}$ materiales producidos dentro del Programa Conectar - Igualdad (ME, 2011), los materiales "Múltiples voces del Bicentenario" y "Explora ciencia ciencias sociales";5 los Operativos Nacionales de Evaluación (en adelante, ONE) y las recomendaciones para la enseñanza surgidos de los mismos (DINIECE, 2008 y 2011); y un conjunto de textos académicos que han señalado los objetivos esperados para la enseñanza. Finalmente, como evidencias de la cultura docente he tomado en consideración las opiniones de cien profesores encuestados en el marco de una indagación realizada desde la UNGS; ${ }^{6}$ observaciones de escuelas y de clases de historia que realicé en el nivel medio en 2012 y $2013 ;{ }^{7}$ carpetas de alumnos, ${ }^{8}$ "Revistas de la Educación Secundaria" editadas por EDIBA; ${ }^{9}$ programaciones de profesores, ${ }^{10}$ entrevistas con profesores y charlas informales mantenidas con docentes de historia al término de las observaciones. ${ }^{11}$

No obstante todas las fuentes consideradas, no podré citar aquí evidencias de todas ellas por razones de extensión por lo que los ejemplos tendrán un carácter más ilustrativo que demostrativo. Por las mismas causas, sólo fundamentaré a continuación el uso de dos fuentes de la cultura docente: carpetas de alumnos y revistas para docentes (puesto que podría pensarse que con las observaciones de clase sería suficiente para reconstruir este aspecto).

Por un lado, he tomado un conjunto de carpetas puesto que en ellas pueden advertirse las actividades que los profesores proponen y los alumnos realizan dentro y fuera del aula de historia. Tomo estas fuentes porque -como afirma Anne Marie Chartier (2002) al trabajar con cuadernos de primaria- entiendo las carpetas como "dispositivos" que permiten advertir las prácticas "ordinarias" no atribuibles a un autor sino acciones que se sostienen por sus actores, por sus "practicantes". Asimismo, tomo en cuenta lo señalado por Silvina Gvirtz (1999) cuando, en su estudio sobre cuadernos de clase, señala que éstos constituyen fuentes relevantes para una investigación que aspira a reconstruir la vida cotidiana de las escuelas porque tienen la capacidad de conservar lo registrado - carácter que lo distingue de otros espacios de escrituración- y porque son espacios de interacción, "una arena donde cotidianamente se enfrentan los actores del proceso de enseñanza y aprendizaje y donde, por tanto, es posible vislumbrar los efectos de esta actividad: la tarea escolar" (GVIRTZ, 1999, p. 12). Además, las carpetas no sólo son el soporte físico de los procesos escolares donde pueden reconocerse los contenidos que se trabajan en las aulas. Como también señala Gvirtz para los cuadernos, las carpetas no son sólo reflejo de las actividades escolares - una especie de memoria neutral de las mismas- sino también constituyen un dispositivo que produce ciertos saberes, un productor de efectos, un soporte que "formatea" y articula de un modo particular 
las prácticas de enseñanza y aprendizaje de historia. No obstante, caben dos salvedades para el caso de las carpetas. Por un lado, no desconozco que, comparado con el cuaderno de primaria, la carpeta de secundaria tiene un carácter más etéreo por su propio formato: se trata de un conjunto de hojas independientes no ligadas a un mismo soporte sino folios que pueden incluirse, mezclarse y quitarse. Por otro lado, no olvido que actualmente los espacios de escrituración en secundaria son variados no sólo por la proliferación de materiales fotocopiables o libros fungibles sino también por la aparición de las netbooks en las aulas. Aun así, entiendo que las carpetas siguen teniendo protagonismo en las aulas y mantienen la capacidad de conservar, aunque sea en parte, el desarrollo de las actividades que se realizan dentro y fuera de la escuela y, por lo mismo, proveen información relevante para reconstruir las prácticas de enseñanza.

Considero, entonces, que las carpetas permiten ver las "invenciones" practicadas, aquellas acciones no decretadas explícitamente pero que son producidas de manera anónima por las "prácticas” constituyendo saberes y prácticas escolares que condensan contenidos, procedimientos, sentidos sobre la enseñanza y el aprendizaje de la disciplina escolar, etc. Finalmente, las carpetas permiten una mirada diacrónica de un curso que es posible observar sólo en algunas pocas clases y también es una fuente que permite reconstruir un cuadro mayor al tener acceso a prácticas no observadas.

Por otro, he tomado en cuenta un conjunto de revistas de "consejos pedagógicos" (particularmente las producidas por Ediba) donde pueden rastrearse qué propuestas se ponen a disposición de los docentes para la enseñanza de la mencionada disciplina. Como señala Finocchio (2009), la producción y circulación de este material dan muestra de un importante fenómeno cultural masivo, industrial y comercial que están dando forma a la práctica docente y al imaginario pedagógico en general. La mencionada autora indica que las revistas de Ediba se presentan como un producto de docentes para docentes y que "en su pacto con el lector, las revisas constituyen una herramienta concreta para el trabajo diario" (2009, p. 201). Las revistas no se detienen en el debate de las corrientes pedagógicas o las modas didácticas sino que, directamente, acompañan y orientan las diversas tareas que encaran los docentes en la escuela: planificación anual, actividades para el aula, láminas y mapas, consignas de evaluaciones, fichas de seguimiento de los alumnos, discursos para las efemérides, obras teatrales para actos escolares, reglamentos de convivencia, entre otros elementos. En síntesis, y dado que Ediba traduce la "cultura normativa" y la "cultura pedagógica" en clave de la "cultura docente", apostando, entre otras cosas, a aquello que para los docentes funciona en la escuela y permite que los alumnos aprendan, las revistas permiten reconstruir la "cultura empírica" de los profesores y de allí mi interés por abordarlas. 
Para cerrar este apartado, señalo que, temporalmente, exploro la enseñanza de la historia en la actualidad considerando las transformaciones de esta disciplina desde la reforma educativa de los '90. Las fuentes documentales - en especial las normativas - tienen en cuenta estos veinte años de reformas mientras que las fuentes empíricas - en particular las observaciones de clases y otras fuentes de la cultura docente - se concentran en los últimos años. Espacialmente, el estudio se concentra en el área metropolitana del gran Buenos Aires específicamente en la región IX de dicha jurisdicción. ${ }^{12}$

A continuación, presentaré el análisis realizado sobre las fuentes atendiendo a la función y el funcionamiento de la historia en el nivel medio en la actualidad tal como aparece enunciado, propuesto y practicado en las culturas política, pedagógica y docente.

\section{Sobre los sentidos de la enseñanza de la historia en la actualidad}

Las fuentes de la cultura normativa en vigencia señalan que la educación secundaria - de carácter obligatorio - tiene como propósito general preparar a los estudiantes para el ejercicio de la ciudadanía, continuar estudios superiores e incorporarse al mundo del trabajo. ${ }^{13}$ En este marco general de regulación, la enseñanza de la historia se encuentra especialmente interpelada. De hecho, las propias leyes nacional y provincial de educación señalan una serie de contenidos curriculares comunes a todas las jurisdicciones que incumben directamente a la enseñanza de nuestra disciplina: el fortalecimiento de la perspectiva regional latinoamericana, particularmente de la región del Mercosur, en el marco de la construcción de una identidad nacional abierta, respetuosa de la diversidad; la causa de la recuperación de las Islas Malvinas, Georgias del Sur y Sandwich del Sur; el ejercicio y construcción de la memoria colectiva sobre los procesos históricos y políticos que quebraron el orden constitucional y terminaron instaurando el terrorismo de Estado, con el objeto de generar en los/as alumnos/as reflexiones y sentimientos democráticos y de defensa del Estado de Derecho y la plena vigencia de los Derechos Humanos. ${ }^{14}$

Asimismo, otros materiales curriculares - como los NAP - ( MECyT, 2006) han señalado que la enseñanza de la historia tiene como sentido principal la construcción de una identidad nacional plural respetuosa de la diversidad cultural, de los valores democráticos y de los derechos humanos; la construcción y apropiación de ideas, prácticas y valores éticos y democráticos que nos permitan vivir juntos y reconocernos como parte de la sociedad argentina; la construcción de una ciudadanía crítica, participativa, responsable y comprometida; y la comprensión sobre el carácter provisional, problemático e inacabado del conocimiento social. 
Una mirada a las fuentes de la cultura pedagógica también permite advertir una serie de propósitos asociados a la enseñanza de la historia. En efecto, desde la reforma educativa abierta en los años noventa, han sido muchos los académicos (historiadores, pedagogos y didactas) que han señalado los propósitos que debería adquirir la mencionada disciplina en el nivel medio. Pero, si queda claro cuáles eran los propósitos que se criticaban y se proponían superar, el cuadro de sentidos y objetivos renovados (que no nuevos) ${ }^{15}$ es, por cierto, más heterogéneo. Enseñar historia para formar la conciencia histórica de los jóvenes (SAAB, 1997); para que los estudiantes comprendan que sus vidas se inscriben en una historia colectiva más amplia (GOJMAN, 1998); para que aprendan que el presente es resultado del pasado (PIGNA, s/f); para que los jóvenes puedan desarrollar un "pensamiento histórico" penetrando en la especificidad de cada momento histórico y de esa manera relativizar y desnaturalizar el presente (PALTI, 2000 y 2010); para que conozcan los modos en los historiadores investigan y piensan críticamente la sociedad (CATTARUZZA, 2002 y 2010), para formar ciudadanos conocedores críticos y comprometidos con su país (ROMERO, 2002 y 1997[2007]) han sido algunas de las muchas formas en que se ha fundamentado la relevancia de la historia escolar en los últimos veinte años.

Otras fuentes de esta misma cultura pedagógica también señalan sentidos renovados para la historia escolar. Así, por ejemplo, en los materiales elaborados para la implementación del programa Conectar Igualdad, se señala que "el conocimiento es un instrumento fundamental para concebir una democracia con igualdad de oportunidades", y a través de los materiales digitales se pretende mostrar los "posibles vínculos entre el conocimiento histórico, las TIC y el razonamiento crítico que debemos impulsar" (ME, 2011, p. 9). Por ello, en los materiales propiamente dichos, se indica que los propósitos son, por un lado, "promover el trabajo en red y colaborativo, la discusión y el intercambio entre pares, la realización en conjunto de la propuesta, la autonomía de los alumnos y el rol del docente como orientador y facilitador del trabajo", y, por otro, "estimular la búsqueda y selección crítica de información proveniente de diferentes soportes, la evaluación y validación, el procesamiento, la jerarquización, la crítica y la interpretación”. ${ }^{16}$ Asimismo, en las secuencias se establecen objetivos específicos relacionados con: conocer hechos y procesos, comprender motivaciones, valorar principios éticos y humanos, identificar relaciones sociales, analizar fuentes históricas, elaborar conclusiones, etc. Del mismo modo, entre las recomendaciones metodológicas para la enseñanza de la historia derivadas de las pruebas de evaluación de calidad, se indican objetivos relacionados con procesos cognitivos tales como reconocer datos, hechos y conceptos, interpretar y explorar fuentes diversas, analizar situaciones, comunicar lo aprendido entre otras cuestiones (DINIECE, 2007, 2008 y 2011). 
Los sentidos y propósitos de la enseñanza de la historia en la cultura docente relevados a través de encuestas y entrevistas a profesores - se muestran en consonancia con lo señalado hasta aquí. En efecto, en una encuesta realizada entre 2011 y 2012 a cien profesores de historia de secundaria, ${ }^{17}$ se les preguntó cuáles eran los propósitos que entendían prioritarios a la hora de enseñar. Dentro de las opciones presentadas, la más elegida fue la de enseñar historia para que los alumnos "desarrollen un pensamiento crítico". En este sentido, el discurso de los docentes se mostró coherente con el de la cultura normativa y pedagógica que, desde la reforma de los 90, viene apostando por superar el aprendizaje memorístico a través de uno que posibilite a los jóvenes construir un pensamiento crítico y fundamentado. Esta tendencia se repitió en las entrevistas y en las charlas informales mantenidas con docentes de secundaria al término de las observaciones de las clases, circunstancia en la que también subrayaron la importancia de una historia para pensar, para entender el presente y pensar el futuro, etc. (cuestiones que además se repiten en otras fuentes como los programas que los docentes elaboran). Al mismo tiempo, los profesores señalaron la importancia de la disciplina dentro de un propósito general de fortalecer los desempeños que permitan a los estudiantes seguir estudiando.

Visto en perspectiva, si durante casi cien años la enseñanza de la historia asumió una función civilizatoria y moralizadora, estipuló la formación de una ciudadanía "espectadora", abonó una identidad patriótica (y cristiana) y construyó una memoria que glorificaba a los héroes del siglo XIX, parece claro que actualmente pondera otros sentidos. Así, la jerarquización de los tiempos contemporáneos, la construcción de la memoria sobre el pasado reciente (donde ya no hay héroes sino víctimas), la introducción de la perspectiva latinoamericana para contribuir a una identidad nacional plural, la formación de ciudadanos democráticos, críticos y participativos está dando cuenta de las rupturas y los cambios. Entre las continuidades, la historia sigue siendo considerada una disciplina escolar fundamental para la conformación de la memoria, la identidad y la ciudadanía aunque desde nuevas valencias.

Todos estos propósitos tienen su traducción en el cotidiano escolar donde veremos - en grados variables - correlaciones, dependencias y autonomías en su funcionamiento.

\section{Sobre las actividades en la enseñanza de la historia en la actualidad}

Como ya he señalado, en el funcionamiento de una disciplina escolar resultan centrales las actividades que se proponen para la enseñanza y el aprendizaje y las fuentes de las culturas escolares aportan evidencias de las estrategias que se señalan, se sugieren y se practican. 
Considerando las fuentes normativas, y observando en particular los diseños curriculares, se pueden ver los medios que se señalan para que los estudiantes alcancen los aprendizajes propuestos, indicando expectativas de logro e incluyendo una serie de recomendaciones y orientaciones didácticas. A modo de ejemplo con relación a las actividades, los diseños vigentes en PBA para 5to año especifican que los alumnos deben "interpretar procesos sociales mundiales, latinoamericanos y argentinos; reconocer la conformación social y económica de América Latina; elaborar hipótesis de interpretación sobre los fenómenos sociales, económicos, políticos y los procesos históricos, reconociendo la diversidad, la multicausalidad y la multiperpectividad en los procesos sociales latinoamericanos y argentinos; comprender las características de la construcción del conocimiento histórico y sus distintas líneas de estudio (historia reciente, política, social, económica, cultural, entre otras)" (PBA-DGCE, 2011, p. 12) a través de la lectura de textos, análisis de fuentes, interpretación de materiales diversos (cine, fotografía), etc. Asimismo, el diseño para 6to año - en la modalidad de Ciencias Sociales y Artes -, puntualiza: “ejercitar prácticas de lectura en las que se promueva el análisis de argumentos, hipótesis y conclusiones; fomentar prácticas de escritura que propongan la elaboración de distintos géneros tales como informes, comentarios bibliográficos, ensayos, entre otros; desarrollar instancias que promuevan las prácticas de investigación de la historia oral" (PBA-DGCE, 2012, p. 39).

Por su parte, diversas publicaciones de didáctica de la historia así como otros materiales muestran también la renovación de la historia escolar en su funcionamiento. Por ejemplo, tanto en las pruebas del ONE como en los informes de sus resultados se señalan como objetivos el "reconocimiento de datos, hechos y conceptos", la "interpretación y exploración" de distintos tipos de fuentes (textos, imágenes, mapas, gráficos, tablas, etc.); el "análisis de situaciones", las "capacidades de comunicación”, etc. (DINIECE, 2007). A partir de las dificultades en los resultados de los operativos de evaluación, las "Recomendaciones Metodológicas para la Enseñanza" (DINIECE, 2008, 2011) señalaron que es necesario preparar secuencias de actividades que requieran poner en juego capacidades cognitivas con diferentes niveles de complejidad, comenzando por algunas sencillas como extraer datos que están explícitos en una fuente, luego poder relacionar esos datos y clasificarlos, realizar inferencias y establecer distintos tipos de relaciones a partir de conocimientos previos, comparar fuentes, formular hipótesis. Para ello, incluyen una serie de actividades que apuntan a la lectura e interpretación de imágenes, tablas estadísticas, letras de canciones, encuestas, gráficos, líneas de tiempo, textos y mapas.

En los libros de textos escolares también es posible advertir que las actividades propuestas apuntan a la búsqueda, lectura y producción de diferentes textos 
así como a la realización de comparaciones, relaciones, análisis, explicaciones multicausales y en multiperspectiva, contextualizaciones, argumentaciones, etc.

Asimismo, en las propuestas didácticas que se vienen publicando para la implementación del programa Conectar Igualdad, se registran actividades que alientan a que los alumnos busquen información, analicen e interpreten fuentes diversas, y produzcan nuevo conocimiento para difundirlo a través de Internet y redes sociales como YouTube, Facebook, Flickr o en blogs (ME, 2011). El énfasis está puesto en acercar a los alumnos a la forma en que se construye el conocimiento histórico, en que los estudiantes formulen preguntas, busquen información, contrasten interpretaciones con el fin de producir y compartir nuevo conocimiento histórico. Por su parte, el material interactivo "Múltiples voces...", se propone una entrada a la historia argentina desde la dimensión política centrada en la utilización de diversos materiales visuales y audiovisuales para la enseñanza.

Ciertamente, desde estas últimas fuentes mencionadas se vislumbran con más claridad los nuevos rumbos para la historia escolar donde los estudiantes son convocados como "lectores, espectadores e internautas" (GARCÍA CANCLINI, 2007), que acceden y pueden trabajar con múltiples lenguajes, soportes y materiales, y que son llamados a buscar y leer, y también a producir y compartir.

Visto en perspectiva, la historia escolar es una disciplina que actualmente propone a los alumnos comprender, analizar, explicar, fundamentar e interpretar procesos históricos mediante textos (escritos, visuales, audiovisuales) y perspectivas diversas. Se trata, como es evidente, de un conjunto de capacidades (llamadas competencias, competencias cognitivas, desempeños, logros, etc.) mucho más complejas que las que se prescribían en el pasado ya que superan con creces la clásica descripción, repetición y memorización de hechos fácticos de un relato canónico presente en textos escritos escolares.

Desde la cultura docente, y en particular a partir de las evidencias registradas en revistas, carpetas y observaciones, también se pueden señalar las actividades que de modo prioritario - aunque no excluyente - se utilizan en la enseñanza de la historia hoy.

Comenzaré por las actividades que proponen las revistas para la educación secundaria de Ediba que provee a los docentes de planificaciones anuales, actividades fotocopiables, proyectos interdisciplinarios, así como láminas entre las que abundan las relacionadas con las conmemoraciones de las efemérides clásicas (es decir, de la historia patriótica). Específicamente en relación con las actividades para las clases de historia, las revistas (en su cuerpo principal y en los cuadernillos fotocopiables) presentan actividades en diálogo con textos, fuentes primarias y secundarias, mapas e imágenes incluyendo cuestionarios de preguntas y otras consignas de análisis 
acompañadas de enunciados para señalar si son "verdaderos o falsos", datos para "unir con flechas", referencias para "ubicar en el mapa", consignas para completar cuadros comparativos e incluso resolver algunas "sopa de letras".

Por su parte, las carpetas de historia de secundaria observadas permiten apuntar la aparición recurrente de tres elementos: cuestionarios, resúmenes (en diversos formatos) y líneas de tiempo. En ocasiones, también se observa el trabajo con materiales cartográficos para la construcción de mapas históricos. Además, aparecen rastros de lecturas de textos, textos escolares, y otros textos arman y seleccionan los mismos profesores, además de fuentes primarias y secundarias, imágenes, recortes periodísticos, obras de arte. También se hallan evidencias de trabajo con películas, a partir de guías de análisis que quedan en las carpetas. De las mismas fuentes se puede inferir que los estudiantes hacen búsquedas en Internet.

Asimismo, las actividades que realizan los alumnos apuntan a buscar, describir, resumir, identificar, explicar, definir, comparar, relacionar, jerarquizar, fundamentar, reconocer, y elaborar conclusiones. Los alumnos escriben respuestas, resúmenes, informes, cuadros, fichas bibliográficas y glosarios. En síntesis, se trata (tal como se ha dicho para el caso de las fuentes de las culturas política y pedagógica) de un conjunto de capacidades más complejas que las que antaño solicitaba la historia como asignatura escolar (que apuntaba a la repetición y la memorización)

No obstante lo anterior, es evidente que no todo lo registrado en las carpetas es pura novedad: algunas actividades muestran las inercias de la historia como disciplina escolar mostrando la potencia de la cultura escolar. En ese sentido, el cuestionario parece ser uno de esos núcleos perennes de la asignatura ya que aparece en papel y en pantallas, es decir, en clases de historia en las que se trabaja con carpetas y en aquellas que se trabaja con netbooks.

Asimismo, las carpetas dan muestra de una serie de actividades que realizan profesores y alumnos y van más allá de la asignatura en sí. Por ejemplo, se registran en varias ocasiones instrucciones para realizar una ficha bibliográfica, para realizar un resumen, para armar un cuadro de llaves lo que parece demostrar el énfasis de algunas prácticas docentes para introducir a los alumnos en "técnicas de estudio" (como se las denominaba antaño) que los habilite para nuevos aprendizajes. También, en ocasiones, profesores y alumnos construyen glosarios dando cuenta de una historia más compleja y conceptual que necesita tener a mano algunas definiciones.

Finalmente, las observaciones realizadas en escuelas y aulas también me han permitido advertir algunas actividades que se plantean en las clases así como aquellas que las trascienden tomando las paredes de los pasillos y salones de actos.

En las aulas, he visto exposiciones de profesores apoyadas por cuadros de síntesis que realizan en el pizarrón (y que los alumnos copian en las carpetas); 
construcción de líneas de tiempo para situar los acontecimientos que se mencionan en las explicaciones; realización de cuestionarios de preguntas y respuestas que se dictan, se realizan y/o se ponen en común en clase; lectura de fuentes históricas; lectura de textos y artículos periodísticos; trabajos de indagación para lo cual los profesores invitan a los alumnos a "buscar información en Internet", a "preguntar a los abuelos", etc. Los alumnos, además, hacen preguntas, formulan hipótesis, realizan inferencias, hacen comentarios de la vida cotidiana en relación con los contenidos de la clase, generan analogías, proponen discusiones sobre todo trayendo al aula cuestiones del presente (y en especial de su presente). También son evaluados oralmente aunque ya no en el formato de "pasar al frente a dar lección", es decir, de pie junto al pizarrón y mirando al resto de los compañeros. En general, los profesores llaman para "dar oral" a algunos alumnos que necesitan recuperar instancias de evaluación, para "levantar" la nota, y lo estudiantes lo hacen sentados al lado de la mesa que ocupa el profesor (mientras el resto del curso realiza otra tarea).

En relación con los materiales, si bien los libros de textos escolares están presentes en las aulas, se registra un uso extendido de fotocopias sueltas o un dossier que preparan los docentes al inicio del año, aún en las escuelas cuyas bibliotecas están dotadas de una gran variedad y cantidad de libros para la enseñanza de la disciplina. Muchos docentes manifiestan la imposibilidad de pedir un libro o la insatisfacción que les produce trabajar con una sola oferta editorial a la que suman, algunas veces, actividades y lecturas extras (sobre todo de fuentes). En ocasiones, además, se hace uso de materiales cartográficos para acompañar y situar las exposiciones docentes y los alumnos construyen algunos mapas históricos, localizando acontecimientos, ciudades, regiones, etc., especialmente en el primer año del ciclo secundario aunque no de manera exclusiva.

Otra de las actividades vista en clases de historia es la realización de láminas que, en algunas oportunidades, trascienden los salones y se exponen en los pasillos de las escuelas. En esos lugares también aparecen carteleras en pizarrones, afiches y ornamentaciones, especialmente dedicadas a las efemérides utilizándose las láminas provistas por las revistas de consejos pedagógicos (antes mencionadas) y ornamentaciones que realizan los preceptores (guirnaldas, palomitas de papel celeste y blanco, etc.). Además, en los pasillos o el hall de la escuela pueden encontrarse exposiciones de producciones realizadas en espacios curriculares -como plástica- que dialogan con otras asignaturas, por caso la historia. De las charlas con los profesores se desprende, además, que las láminas cumplen el rol de hacer más ameno el lugar de trabajo que muchas veces, en las escuelas públicas, presenta paredes desgastadas y rotas. Así, hay una búsqueda de generar un espacio ameno de trabajo y de convivencia en medio de la fragmentación y la desigualdad material. 
Desde mi punto de vista, las láminas también demuestran la potencia de la cultura escolar. En la formación de un profesor de secundaria en la actualidad, la confección de láminas no es un contenido de su trayecto formativo. Y, sin embargo, las láminas y afiches están en las aulas como muestra de tradiciones, regularidades y reglas de juego que se transmiten de generación en generación y que proporcionan estrategias para integrarse en dichas instituciones, para interactuar y para llevar a cabo, sobre todo en el aula, las tareas cotidianas que de cada uno se esperan (VIÑAO, 2002). Las láminas tienen un papel importante como expresión del trabajo de los alumnos pero ya no son, como en el pasado, "un elemento para la apreciación sensible, para brindar la base del conocimiento" (FELDMAN, 2004, p. 79).

Desde luego, a lo que he observado in situ pueden sumarse otras evidencias (derivadas de las aulas virtuales y blogs de los profesores) que muestra otras actividades, recursos, formatos y soportes entre los cuales abundan las posibilidades derivadas del uso de TIC que, a su vez, incluyen y combinan materiales diversos (videos documentales, películas, audios, presentaciones en power point, líneas de tiempo que a su vez contienen textos, fotografías y videos). En estos casos, se ponen a disposición de los estudiantes diversos materiales multimediales al tiempo que esos sitios albergan diversas producciones de los alumnos.

Dicho esto, realizaré algunos comentarios en torno a estos tres elementos sobresalientes en las carpetas de historia: cuestionarios, síntesis y líneas de tiempo.

De una parte, los cuestionarios aparecen como un elemento central en las carpetas. Como han señalado otros autores (por ejemplo, AISEMBERG, 2005), se trata de una actividad clásica en la enseñanza de la historia, aunque en ocasiones se presenta con preguntas atomizadas que provocan que los alumnos desplieguen estrategias de localización de la información necesaria para responder. ${ }^{18}$ No obstante lo anterior, también las carpetas señalan que los estudiantes expliquen, comparen, elaboren conclusiones y den opiniones. En relación con este último aspecto, he encontrado de manera recurrente en las carpetas (y también en las revistas citadas) consignas que apelan a los estudiantes a que den sus opiniones, argumenten sus posiciones, compartan sus sensaciones y den cuenta de sus sensibilidades. ${ }^{19}$

De otra, las síntesis toman diversos formatos: resúmenes escritos o graficados en forma de cuadros, esquemas y redes que reproducen aquello que sostiene la exposición del profesor y se anota en el pizarrón. En general, los esquemas toman la forma de secuencias derivativas (una idea general que se abre en múltiples ideas secundarias conexas). Los mismos parecen dar cuenta de ciertas ideas que han tenido alto impacto en la normativa y el imaginario pedagógicos post-reforma: que el aprendizaje - conforme a la teoría de Ausubel - se produce por asimilación de contenidos en sucesivo grado de diferenciación y especificación. De allí que se haya 
producido la adhesión entre construcción de redes y aprendizaje significativo. ${ }^{20}$ Asimismo, esos cuadros y gráficos incluyen conceptos además de datos, por lo que también se puede tomar como rastro de una nueva historia más compleja y explicativa donde no sólo hay datos para repetir sino nociones más amplias para comprender.

Finalmente, las líneas de tiempo aparecen recurrentemente (en especial al iniciar una unidad didáctica) y denotan un trabajo que no avanza hacia el establecimiento de periodizaciones que contribuirían a explicar los procesos históricos puesto que responden a determinadas maneras de interpretar el pasado desde el presente (PAGÈS, 1997). Esta insistencia en la ordenación de hechos, datos y procesos en una línea puede ser entendida como una táctica que los profesores despliegan frente a sus alumnos a los que encuentran inmersos en una experiencia de tiempo fugitiva, fragmentada y evanescente (DUSCHATZKY, 2003). En otras palabras, interpreto que esta actividad no es tanto la demostración de la persistencia de cánones positivistas o de una certeza didáctica en torno a la importancia de los hechos y acontecimientos, sino como respuesta situada frente a unos alumnos que, pertenecientes a otra generación, manejan una temporalidad diferente a la que se pretende transmitir en clases de historia.

Para concluir en torno a lo rastreado en las fuentes de la cultura docente, puede señalarse que la enseñanza de la historia en las aulas muestra algunas influencias de las nuevas regulaciones de la cultura normativa y de lo sugerido en la cultura pedagógica. Asimismo, muestra los "haceres ordinarios" (CHARTIER, 2000), las respuestas que desde la práctica se ensayan para hacer frente a procesos que superan con creces las cuestiones estrictamente didácticas e historiográficas. Así, para hacer frente a la fragmentación y desigualdad educativa se producen y se cuelgan láminas que también se hacen para que los alumnos aprendan a resumir y exponer; para actuar frente a las transformaciones en las subjetividades juveniles, se insiste con el tiempo histórico en líneas cronológicas; para afrontar los cambios que ocasiona la obligatoriedad del nivel medio, se explicitan técnicas de estudio, de resumen, de redacción, etc. Y también pueden verse persistencias en algunos de esos mismos elementos. De hecho, ¿por qué aparecen la resolución de cuestionarios o la elaboración de láminas que ya no se prescriben la cultura política ni se recomiendan en la cultura pedagógica? Esto sucede porque la cultura profesional docente tal como se ha construido (y se construye cotidianamente) es una "tradición inventada desde la experiencia, distinta al conocimiento experto" (ESCOLANO, 1999, p. 25). En síntesis, lo se puede registrar desde las fuentes de la cultura docente son convergencias pero también distancias con las culturas política y pedagógica puesto que la cultura docente tiene su propia lógica y las prácticas de los profesores pueden ser concebidas como 
[...] operaciones que en cierto modo reparan, remiendan y arreglan - con los elementos que maestros y profesores hallan disponibles- los propósitos y orientaciones de propuestas generadas a partir de intereses, informaciones, mentalidades y exigencias institucionales muy diferentes, incluso por momentos opuestas, a las que se derivan de la práctica y profesión docente (FINOCCHIO, 2003, p. 84).

\section{Herencias, rupturas, invenciones e inercias de la historia como disciplinar escolar}

Roger Chartier (2007) señala que la lectura de las diferentes temporalidades que hacen que el presente sea lo que es - herencia y ruptura, invención e inercia - sigue siendo la tarea singular de los historiadores para con sus contemporáneos. Por mi parte, asumo como propia esa labor al abordar la enseñanza de la historia en la actualidad.

A propósito de esas temporalidades, me vuelve una anécdota de mi trabajo de campo, cuando consulté a dos profesores sobre la posibilidad de realizar observaciones de clases de historia. Ante mi solicitud, ambos me preguntaron "-ipara quée?. Para evitar suspicacias, rápidamente contesté “-para ver cómo se enseña hoy", y en un guiño de complicidad generacional agregué: "-seguramente es diferente a cuando nosotros íbamos a la escuela". Ante esto, uno de ellos me contestó "-no, en las clases de historia se hacen las mismas cosas de siempre". El otro me dijo "-sí, la enseñanza de la historia ya no es lo que era".

¿Cómo tomar esos comentarios? "La enseñanza de la historia ya no es lo que era" y "en las clases de historia se hacen las mismas cosas de siempre" son afirmaciones que pueden evidenciar nostalgias de un pretendido paraíso perdido o supuestas inmutabilidades de las prácticas escolares. Una mirada así no permite advertir las temporalidades mixturadas y heterogéneas que se juegan en la escuela, supone sólo lo que perdura desconociendo lo que emerge, elude las reinscripciones constantes de sentido en función de las nuevas condiciones, e invisibiliza los saberes y prácticas inscritas en las disparidades propias del tiempo (FINOCCHIO, 2011).

Desde otros sentidos, esas mismas palabras nos pueden servir para señalar tanto las transformaciones y rupturas que surgen en el presente (y las que se avizoran a futuro) como las permanencias y adaptaciones. Desde esta perspectiva, "lo mismo de siempre" puede dar cuenta de la perdurabilidad de cultura escolar que, en algunos de sus rasgos más visibles, apenas se ha modificado (como la división de saberes por asignaturas). También "lo de siempre" aparece cuando vemos profesores exponiendo, presentando cuestionarios, o haciendo que sus alumnos lean textos escritos. En efecto, esos elementos estaban en el pasado y se repiten hoy. Desde esta misma perspectiva, "lo que ya no es" puede aludir a las nuevas características que tiene la historia escolar en función de la reforma de contenidos y sentidos 
desde los '90; puede referir a los nuevos desafíos que enfrenta, si consideramos las transformaciones culturales y sociales que interpelan a la escuela; puede denotar nuevos rumbos, que se nos muestran en diversos textos y prácticas de lectura, variados lenguajes y soportes que están presentes en las aulas (aunque de modo desigual), las diversas actividades que apelan a la construcción de contenidos y sentidos por parte de los alumnos.

La indagación presentada en parte aquí me permite señalar que la enseñanza de la historia hoy muestra una variada gama de herencias e inercias pero también de rupturas e invenciones que ponen en evidencia el quiebre el código que durante más de cien años caracterizó a la historia disciplinar. En aquel código sobresalía lo moralizador, lo civilizatorio, lo patriótico y chauvinista; la memoria del lejano siglo XIX; y la memorización de textos escritos eminentemente narrativos que debían repetir aquellos pocos que accedían a este nivel de escolaridad. Hoy, la enseñanza de la historia está planteando otras ideas y sentidos: la jerarquización de los tiempos contemporáneos, la democracia, la identidad nacional plural en un contexto regional más amplio; una historia para formar ciudadanos democráticos, críticos y participativos; una historia más conceptual y explicativa; una historia que apela a diversas fuentes; una historia que forma parte de una secundaria obligatoria.

Desde luego, estamos lejos de encontrarnos frente a un código nuevo y estabilizado. De hecho una comparación entre algunos enunciados de la reforma de los 90 y la iniciada hacia 2006 nos haría matizar algunas líneas. Pero, por lo pronto, ni todo tiempo pasado fue mejor, ni la enseñanza de la historia hoy está en medio de la tragedia educativa; como tampoco todo lo que actualmente se registra nos complace y supera el supuesto oscuro pasado de nuestra disciplina escolar (del que por cierto, hay mucho por indagar).

Vivimos un tiempo de transición (cultural, social, comunicacional, educativa) y la enseñanza de la historia está dando muestras de sentirse interpelada y responder -como sabe y como puede- a los nuevos rumbos. Y es que la historia, como disciplina escolar, es una construcción histórica y por tanto puede cambiar. Como historiadores sabemos que en ese proceso habrá contradicciones, herencias, rutinas, rupturas, inercias, idas y vueltas como las que aquí he intentado mostrar. 


\section{Teaching of history in the secondary level in Argentina: inheritance, inertias, breaks and inventions}

\section{Abstract}

This work analyses the history school discipline in the secondary level in Argentine, especially the objectives and activities. Across such sources the analysis shows breaks, inertias, inventions and legacies.

Keywords: Teaching. History. Practices. Objectives. Activities.

\section{Notas}

1 Presentaré algunos avances de una investigación mayor en curso titulada Saberes y prácticas docentes en historia en el nivel medio (proyecto de Carrera de Investigador Científico de CONICET) ofreciendo algunas evidencias y reflexiones iniciales mas no una lectura acabada del problema.

2 Sin dudas, entre ambos elementos debe darse una necesaria interacción aunque no discutiremos este aspecto en extensión. Asimismo, no podemos dejar de relacionar estas dimensiones con los contenidos pero no serán objeto de este trabajo.

3 . Si bien retomo la clasificación propuesta por Escolano, considero que la cultura docente no es solo empírico-práctica sino que reúne aspectos teóricos y prácticos. Asimismo, y aun tomando los conceptos de "culturas de la escuela" de Escolano - que me resultan muy operativos- sigo a Viñao (2002, p. 78) cuando señala que esta triple distinción "resulta extremadamente útil siempre y cuando no se olviden las alianzas temporales que suelen establecerse entre la cultura de los expertos y la de los reformadores y gestores". Personalmente agrego que en ocasiones se visualizan superposiciones ya que el discurso pedagógico puede ser transmitido por el discurso normativo (bajo la forma de sugerencias didácticas y materiales de desarrollo curricular y evaluación) al tiempo que la cultura de los docentes también puede encontrar canales de comunicación en la cultura pedagógica o incluso tomar en apariencia sus formas.

4 Longseller, 2010; Estada, 2011; Santillana, 2011; Kapelusz, 2013.

5 Disponibles en: http://explora.educ.ar/curso-de-ciencias-sociales/otros-materiales-curso-de-ciencias-sociales/y http://vocesbicentenario.educ.ar/

6 "La enseñanza de la historia en secundaria hoy" que dirijo en el IDH y en el cual participan E. Geoghegan, S. Carnevale y Y. Billán.

7 Personalmente, entre 2012 y 2014, realicé observaciones de clases en 8 aulas diferentes en diversos tipos de escuelas -(siguiendo las categorías señaladas por Tiramonti (2004) - y sumando un total de 48 horas reloj de observaciones.

8 Se trata de un corpus de veinte carpetas de historia de secundario de estudiantes de escuelas (públicas y privadas) de los partidos de: Malvinas Argentinas, San Miguel, José C. Paz, Moreno, Hurlingham y Tigre recogidas en los cursos escolares de 2009 a 2013.

9 Se trata de un corpus de diez revistas tomadas al azar entre las editadas entre 2008 y 2011.

${ }_{10}$ Varios de los profesores observados accedieron a compartir sus programaciones (5) a las cuales sumé otras programaciones de cursos no observados (5 más).

11 Hasta la fecha, realicé entrevistas con 5 de los 9 profesores observados y con todos mantuve charlas informales al inicio y finalización de las observaciones de clases que también me aportaron datos relevantes para la interpretación de datos.

12 La región IX de Provincia de Buenos Aires coincide con el área de influencia de la Universidad Nacional de General Sarmiento donde desarrollo esta pesquisa.

${ }^{13}$ Véase Ley Nacional 26206, art. 29 (ME, 2006).

${ }^{14}$ Ley Nacional 26206, artículo 92, incisos a, b y c (ME, 2006) y Ley Provincial 13688, artículo 107, incisos a, b y c (PBA-DGCE, 2008).

15 Hablo de "renovados" y no de "nuevos" ya que algunos enunciados pueden ser rastreados en la historia que se pretendía superar. Por ejemplo, en un documento curricular de la última dictadura militar también puede leerse que se esperaba que, a través de la historia, el alumno "ejercite la lectura reflexiva y 
desarrolle el espíritu crítico" (MCE, 1980). Y, sin embargo, no puede soslayarse que ese enunciado estaba ligado a "valorar la historia nacional y la obra de los hombres próceres como arquetipos en la orientación de las conductas personales y sociales" y comprender "el error de los determinismos, en especial el de las concepciones materialistas que niegan la libertad y la trascendencia del hombre".

16 Véase por ejemplo, http://www.educ.ar/dinamico/UnidadHtml_get_0851d09d-c855-11e0-81e0e7f760fda940/index.htm

17 Sobre la presentación de la encuesta, véase Gonzalez y Billán (2011). Para un análisis de alguno de sus resultados, puede consultarse Gonzalez, Carnevale y Billán (2012).

${ }_{18}$ Esta limitación ya era criticada a principios del siglo XX: Marion (1908, p. 152 citado por CHERVEL, 1991, p. 87) señalaba que "el análisis no basta; debe completarse con la síntesis. Porque conocer las cosas no es conocer sólo los elementos que las componen, sino también las relaciones que se establecen entre ellos".

${ }^{19}$ Por ejemplo, consignas tales como "cuál es tu opinión respecto...?”; “¿qué crees que expresa este poema...?”: “¿qué opinión te merece....?”; ¿cuál considerás que ....?”; "elaborá una reflexión personal sobre...”

${ }^{20}$ Sobre la relación entre redes conceptuales y aprendizaje significativo véase Novak, J.; Gowin, B. (1988). Aprendiendo a aprender. Barcelona: Martínez Roca.

\section{Referências}

AISEMBERG, Beatriz. La lectura en la enseñanza de la historia: las consignas del docente y el trabajo intelectual de los alumnos. Lectura y vida, Buenos Aires, v. 26, n. 3, p. 22-31, agosto. 2005

BRASLAVSKY, Cecilia. La historia en los libros de texto de ayer y de hoy para las escuelas primarias argentinas. En: AISENBERG, Beatriz; ALDEROQUI, Silvia (Comps.) Didáctica de las Ciencias Sociales. Aportes y reflexiones. Buenos Aires: Paidós, 1994. p. 115-136.

BRITO, Andrea. Los profesores y la escuela secundaria, hoy. Notas sobre una identidad en repliegue. Buenos Aires: Libros Libres, 2010.

CASTELLS, Manuel. La era de la información. Madrid: Alianza, 1998

CATTARUZZA, Alejandro. La historia en tiempos difíciles. Revista TodaVIA, 2. Buenos Aires, v. 2, n. 1, p. 26-29, sept. 2002 Fundación OSDE.

. Panel inaugural del ciclo: Historia ¿Para qué? En: CERNADAS, J. \& LVOVICH, D. (Eds.). Historia ¿Para qué? Revisitas a Una Vieja Pregunta, Buenos Aires: Prometeo-UNGS, 2010. p. 25-32.

CHARTIER, Anne Marie. Fazeres ordinários da classe: una aposta a pesquisa e para a formação. Educação e pesquisa, São Paulo, v. 26, n. 1, p. 57-168, jan./jun. 2000.

. Um dispositivo sem autor: cadernos e fichários na escola primária. Revista Brasileira de História da Educação, São Paulo, v. 2, n. 3, p. 9-26, jan./jun. 2002

CHARTIER, Roger. La historia o la lectura del tiempo. Barcelona: Gedisa, 2007.

CHERVEL, André. Historia de las disciplinas escolares: reflexiones sobre un campo de investigación. Revista de educación, Madrid, v. 295, n. 1, p. 59-111, mayo/agosto 1991.

CHEVALLARD, Yves. La transposición didáctica. Del saber sabio al saber enseñado. Buenos Aires, Aique, 1997.

CUESTA, Raimundo. Sociogénesis de una disciplina escolar: la historia. Barcelona - Pomares-Corredor, 1997. 
DE AMÉZOLA, Gonzalo. Esquizohistoria. La historia que se enseña en la escuela, la que interesa a los historiadores y un cambio posible de la historia escolar. Buenos Aires: Libros del Zorzal, 2008.

DUSCHATZSKY, Silvia. La escuela entre tiempos. En: DUSSEL, I.; FINOCCHIO, S. (Comps.) Enseñar hoy. Una introducción a la educación en tiempos de crisis. Buenos Aires: FCE, 2003. p. 93-101.

DUSSEL, Inés; FINOCCHIO, Silvia (Comps.) Enseñar hoy. Buenos Aires: FCE, 2003.

ESCOLANO, Agustín. Los profesores en la historia En: Magalhaes, J.; Escolano, A. (Eds.). Os profesores na historia. Porto: Sociedade Portuguesa de Ciências da Educação, 1999. p. 15-27.

FELDMAN, Daniel. Imágenes en la historia de la enseñanza: la lámina escolar. Educaçao \& Sociedade, Campinas-SP, v. 25, n. 86, p. 75-101, abr. 2004.

FINOCCHIO, Silvia. Cambios en la enseñanza de la historia: la transformación argentina. Iber: Didáctica de las Ciencias Sociales, Geografía e Historia, Barcelona, v. 22, n. 1, p. 17-30, marzo 1999.

. Apariencia escolar. En: DUSSEL, I.; FINOCCHIO, S. (Comps.) Enseñar hoy. Una introducción a la educación en tiempos de crisis. Buenos Aires: FCE, 2003. p. 81-87.

La escuela en la historia argentina. Buenos Aires: Edhasa, 2009.

Los docentes, los saberes y la mutación de la escuela. En: FINOCCHIO, S.; MONTES, N. (Comps). Saberes y prácticas escolares, Rosario: HomoSapiens, 2011, p. 175-199.

. Cambios en la enseñanza de la historia: la transformación argentina. Iber: Didáctica de las Ciencias Sociales, Geografía e Historia, Barcelona, n. 22, p. 17-30, oct./dec. 1999. Disponível em: <http://iber.grao.com/revistas/iber/022-la-historia-en-la-ensenanza-iberoamericana>. Acesso em: 15 maio 2014.

GARCÍA CANCLINI, Nestor. Lectores, espectadores e internautas. Barcelona: Gedisa, 2007.

GOJMAN, Silvia. La historia: una reflexión sobre el pasado. Un compromiso con el futuro. En: AISENBERG, B. \& Alderoqui, S. (Comps.) Didáctica de las Ciencias Sociales: Aportes y reflexiones. Buenos Aires: Paidós, 1998. p. 42-62.

GONZALEZ, María Paula et al. Los profesores y la enseñanza de la historia hoy: entre sentidos, expectativas, condiciones y opciones. En Actas de las IV Jornadas Internacionales de Enseñanza de la Historia y XIII Jornadas de Investigación y Docencia de la Escuela de Historia (en CD room), 2012.

GONZALEZ, Maria Paula; BILLAN, Yésica. Sentidos y prácticas docentes. La trastienda teórica y metodológica de una investigación. En Actas de las III Jornadas Internacionales de Enseñanza de la Historia y XII Jornadas de Investigación y Docencia de la Escuela de Historia (en CD room), 2011.

GOODSON, Ivor. La construcción social del currículum. Posibilidades y ámbitos de investigación de la Historia del currículo. Revista de Educación, Madrid, v. 295, n. 1, p. 7-37, mayo/agosto. 1991. 
GVIRTZ, Silvia. El discurso escolar a través de los cuadernos de clase: Argentina 1930-1970. Buenos Aires: Eudeba, 1999.

JULIA, Dominique. A cultura escolar como objeto histórico. Revista Brasilera de História da Educação, São Paulo, n. 1, p. 9-43, jan./jun. 2001.

KESSLER, Gabriel. La experiencia escolar fragmentada. Estudiantes y docentes en la escuela media de Buenos Aires. Buenos Aires: IIPE - UNESCO, 2002.

LANZA, Hilda. La propuesta oficial y la propuesta editorial para la enseñanza de la historia en la escuela media. En Lanza, H \& Finocchio, S. Curriculum presente, ciencia ausente. La enseñanza de la historia en la Argentina de hoy Buenos Aires: FLACSO/ CIID- Miño y Dávila Editores, 1993, p. 17-95.

PAGÈS, Joan. El tiempo histórico. En: BENEJAM, P.; PAGÈS, J. (Coords.) Enseñar y aprender Ciencias Sociales, Geografía e Historia en la Educación Secundaria, Barcelona: Horsori, 1997. p. 189-208.

PALTI, Elias. Intervención en el foro ¿Qué historia vamos a enseñar en el nuevo siglo? Debate educativo de Historia a debate, 2000. Disponible en: <http://www.h-debate.com>. Aceso en: 11 agosto 2009.

. Panel inaugural del ciclo: Historia ¿Para qué? En J. Cernadas \& D. Lvovich (Eds.) Historia ¿Para qué? Revisitas a una vieja pregunta, Buenos Aires: Prometeo-UNGS, p. 38- 45, 2010

PIGNA, F. (s/f) ¿Cuándo empezó la historia?. Disponible en: <http://www.elhistoriador.com.ar/ aula/antigua/cuando_empezo_la_historia.php>. Aceso en: 5 nov. 2011.

ROMERO, Luis A. Volver a la historia. Buenos Aires: Aique, 1997/2007.

. El desafío de formar el ciudadano patriota. Ponencia presentada en la Conferencia en el III Congreso Nacional de Educación. II Internacional, organizado por la Universidad nacional de Córdoba y la Unión de Educadores de la provincia de Córdoba. Córdoba, 3, 4 y 5 de octubre de 2002 .

. (Coord.). La Argentina en la escuela. Buenos Aires: Siglo XXI, 2004.

SAAB, Jorge. El lugar del presente en la enseñanza de la historia. Quinto Sol, 1, La Pampa: UNLPam, p. 147-167, 1997.

TENTI FANFANI, Emilio (Comp.). Educación media para todos. Los desafíos de la democratización del acceso. Buenos Aires: OSDE-Ed. Altamira, 2003.

TIRAMONTI, Guillermina; MONTES, Nancy (Comps.). La escuela media en debate. Buenos Aires: Manantial, 2008.

TIRAMONTI, Guillermina (Comp). La trama de la desigualdad educativa. Mutaciones recientes en la escuela media. Buenos Aires: Manantial, 2004.

URRESTI, Marcelo. Nuevos procesos culturales, subjetividades adolescentes emergentes y experiencia escolar. En: TENTI, E. (comp.). Nuevos temas en la agenda de política educativa, Buenos Aires: Siglo XXI, 2008. p. 101-124.

VIÑAO, Antonio. Sistemas educativos, culturas escolares y reformas: continuidades y cambios. Madrid: Morata, 2002. 
Documentos y fuentes consultadas

Libros escolares

ANDUJAR, Andrea et al. Historia: Argentina y el mundo: la segunda mitad del siglo XX. Buenos Aires: Santillana, 2011.

CANESSA, Julio; SERRANO, Gerardo y PAURA, Vilma. Historia. La Argentina: ¿Un país a la deriva? Desafíos y alternativas (1930 hasta la actualidad). Buenos Aires: Longseller, 2010

PÉREZ, Mariana et al. Historia de la Argentina. Buenos Aires: Kapelusz, 2013.

TATO, María Inés; BUBELLO, Juan Pablo; CASTELLO, Ana María. Historia 5ES: la segunda mitad del siglo XX. Buenos Aires: Estrada, 2011.

Documentos de la DINIECE

DINIECE. Material de apoyo para docentes y estudiantes. Ciencias Sociales. ONE 2007 Etapa 2008. Buenos Aires, Publicación del Ministerio de Educación, 2007.

Recomendaciones metodológicas para la enseñanza. Ciencias Sociales. ONE 2007/2008

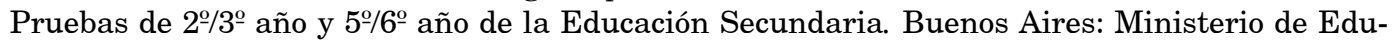
cación, 2008.

. Recomendaciones metodológicas para la enseñanza. Ciencias Sociales. ONE 2010. Pruebas de $2^{\circ} / 3^{\circ}$ año y 5\%/6ํㅡo año de la Educación Secundaria. Buenos Aires: Ministerio de Educación, 2011.

Leyes y diseños curriculares

ME. Argentina, Ministerio de Educación. Programa Conectar Igualdad. Serie estrategias en el aula para 1 a 1. Historia. Ciclo orientado. 2011. Disponible en: <http://secuencias.educ.ar/course/ category.php?id=23>.

. Argentina, Ministerio de Educación. Ley Nacional de Educación 26206. Buenos Aires: Publicaciones del Consejo Federal de Educación, 2006.

Argentina, Ministerio de Educación. Programa Conectar Igualdad. Serie estrategias en el aula para 1 a 1. Historia. Ciclo orientado. 2011. Disponible en: <http://secuencias.educ.ar/ course/category.php?id=23>.

MCE. Argentina, Ministerio de Cultura y Educación. Guía programática-Historia. Buenos Aires: Publicación del Ministerio, 1980.

MECyT. Argentina Ministerio de Educación, Ciencia y Tecnología. Núcleos de Aprendizajes Prioritarios. Disponible en: <http://www.me.gov.ar/curriform/publica/nap/nap3socia.pdf>. 2004.

. Argentina. Ministerio de Cultura y Educación. Ley Federal de Educación 24195. Buenos Aires: Publicaciones del Consejo Federal de Educación, 1993. 
PBA-DGCE. Provincia de Buenos Aires, Dirección General de Cultura y Educación. Diseño Curricular para la Educación Secundaria $5^{\circ}$ año: Historia. La Plata: Dirección General de Cultura y Educación de la Provincia de Buenos Aires. 2011.

Provincia de Buenos Aires, Dirección General de Cultura y Educación. Diseño Curricular para la Educación Secundaria $6^{\circ}$ año: Historia (Modalidad Artes y Ciencias Sociales). La Plata: Dirección General de Cultura y Educación de la Provincia de Buenos Aires. 2012. 